\title{
Study to Establish New Marine Aids to Navigation at Kuantan Port New Deep Water Terminal
}

\author{
Ahmad Faizal Bin Ahmad Fuad ${ }^{a}$, Nur Syamimi Binti Abdul Aziz ${ }^{\mathrm{b}}$, Mohd Hafizi Bin Saidc and \\ Mohammed Ismail Russtam Suhrab
}

School of Ocean Engineering, Universiti Malaysia Terengganu, Terengganu, Malaysia a.faizalfuad@hotmail.com,b.emailnursyamimi642@gmail.com,c.hafizi@umt.edu.my d.m.ismail@umt.edu.my

Keywords: $\quad$ Aids to Navigation, Port, Simulation

\begin{abstract}
Kuantan Port is situated facing the South China Sea on the east coast of Peninsular Malaysia. The port has three main types of berths with a total length 4013 meters. The longest berth is the liquid cargo berth, which is 1740 meters, follows by multi-purpose berth of 1673 meters and container berth of 600 meters. Currently, Kuantan Port is undergoing an upgrading process with the construction of a new deep water terminal that adds a new container terminal to the port. The project consists of construction of a new container terminal, construction of a breakwater, dredging of the new port basin and navigation channels and establishment of new marine aids to navigation. The purpose of this paper is to review the design of the propose new channel and to propose the type and configuration of new marine aids to navigation according to the PIANC and IALA guidelines. The proposal to establish the marine aids to navigation, which is in the form of simulation was developed by using the Multigen software, which is an area development software for the Full Mission Ship Simulator. The simulation is the practical and a near realistic form to validate the proposal.
\end{abstract}

\section{Introduction}

Kuantan Port is the largest multipurpose sea port in the east coast Peninsular Malaysia that facing the South China Sea. The chart of the port is shown in Fig. 1. The port had started its operation since 1980. The existing port has 11 multipurpose break bulk and dry bulk berths with maximum draft 11.2 meter and able to accommodate vessels up to 45,000 displacements tonnes [1]. The port has three container berths measuring 600 metres with capacity of 400,000 TEUs per year. The liquid bulk facilities are four liquid berths and four liquid chemical berths [1]. The port has diversified its cargo handling initially from timber and palm oil to liquid chemical products and container. This progress is in line with current need, namely to support the Gebeng petrochemical industry that situated around $9 \mathrm{~km}$ from the port.

The economic development east coast region has been growing fast and the current port capacity is unable to cater for the future demand. Therefore, to meet with the demand, a New Deep Water Terminal (NDWT) has been constructed since 2013, which able to accommodate bulk carriers of up to 200,000 DWT and container ships of up to 18,000 TEUs. Upon completion, the new terminal is expected to double its cargo capacity to 52 million tonnes and position Kuantan Port as the main gateway to the Asia Pacific and China. The completion and operation of the first phase NDWT will starts in the mid of 2018 [2]. 


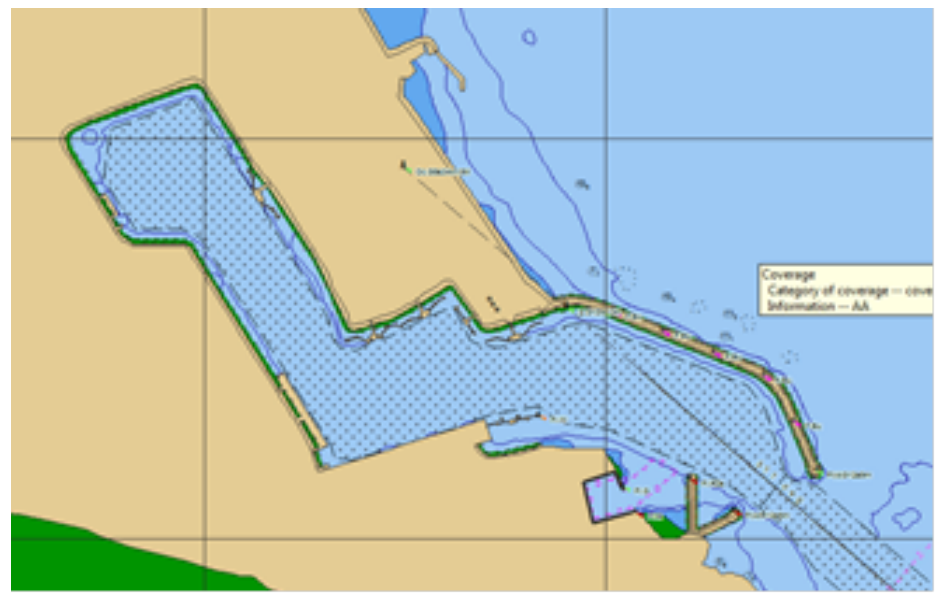

Figure 1: The caption of electronic chart of the existing Kuantan Port without the New Deep Water Terminal

However, with the construction of the NDWT, the shipping channel to the port need to be redesign and the marine aids to navigation that mark the channel need to be reconfigured accordingly. Therefore, the purpose of this study is to propose a new design of shipping channel to the port according to the design of NDWT and to propose new configuration of marine aids to navigation for the new channel.

\section{Methodology}

The flow chart of methodology is shown in Fig. 2. The detail explanation of the methodology as follows. The first step was to conduct a literature review related to the design of shipping channels and configuration of marine aids to navigation. The second step was to conduct site observation by taking photographs and record positions of related structures at Kuantan port including the under construction NDWT. The detail construction plan of NDWT was also gathered in this stage. The third step is to develop the three dimensional area of Kuantan Port with NDWT by using the information gathered in step two and relevant nautical chart. The development of the three dimensional area was using Multigen Presagis software, which the output of the software compatible is with the Kongsberg Ship Simulator. The fourth step is to design the shipping channel according to the international standard and size of vessels that called Kuantan Port. The fifth step is to configure the arrangement and type of marine aids to navigation according to international guidelines.

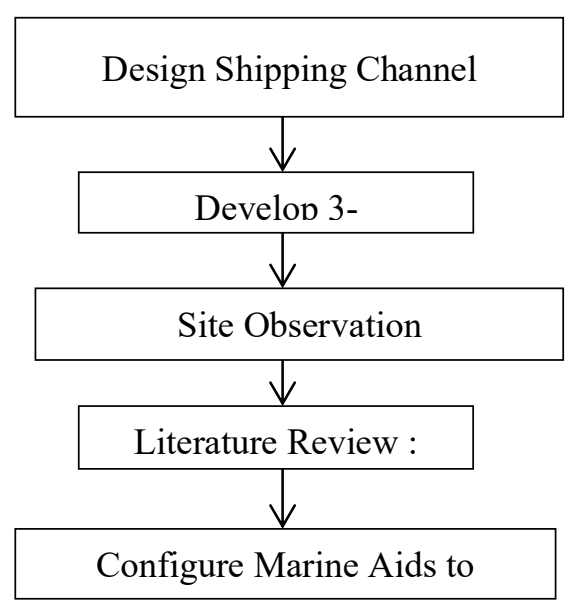

Figure 2: Flow chart of research activities 


\section{Results and Discussions}

\subsection{The Three-Dimensional Area of Kuantan Port}

The developed three-dimensional area of Kuantan Port is shown in Fig. 3.

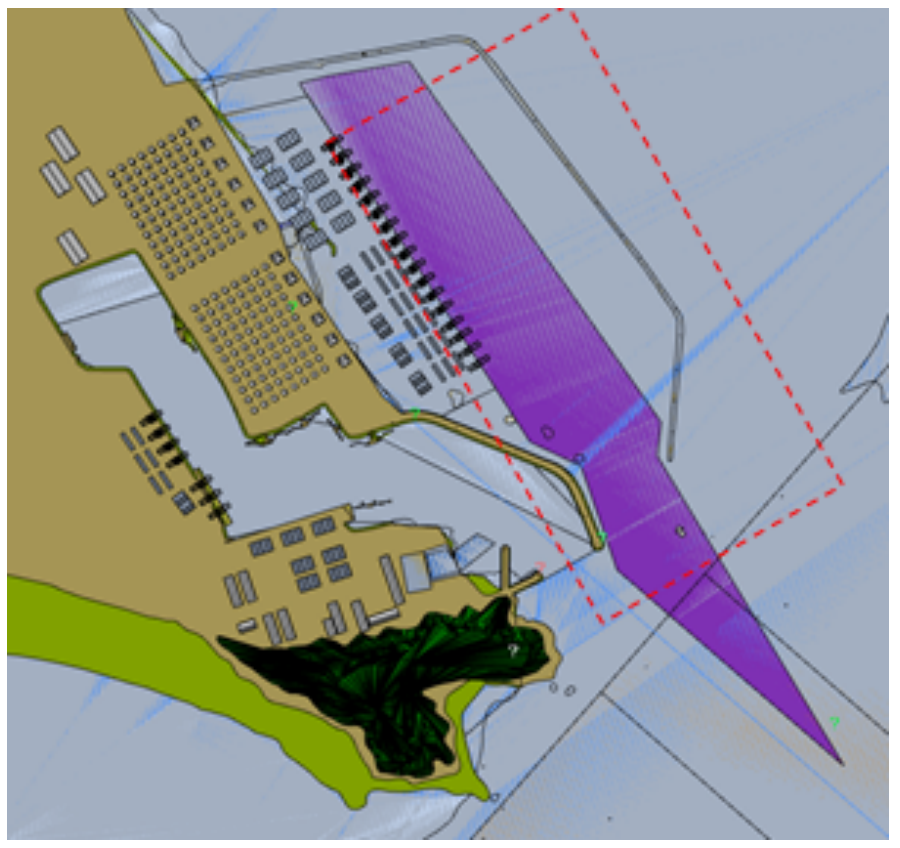

Figure 3: Kuantan Port 3-dimensional Area

The NDWT is the part of the port from the outer breakwater to the new container terminal, as marked by the red dash line in Fig. 3. The NDWT is under construction during the writing of this article. The existing part of the port started from the inner breakwater (middle of the simulation area) to the rest of the left part of the area.

The width of the channel between the existing breakwater and the under construction breakwater is around 430 metres, as shown by the double arrow in the figure. The depth of the magenta area will be dredged to 16 meters depth. The aforementioned channel width and depth would allow the size of container vessel of around 150000 DWT to operate in the NDWT. These sizes are parallel with the New Panamax class vessel with dimensions of length overall 366 meters, beam 49 meters and draft 15.2 meters [3]. The example of such vessel is MV COSCO Guangzhow, with the capacity of 9500 teu. The port operator designed the turning basin to be 600 meters diameter circle area as shown by the red dash oval line in Fig. 4. The sheltered area within the breakwater of NDWT is expected to be calm and the movement of vessel is assisted by tugs, therefore the dimension of turning basin required is 2 times length overall of vessel, which is the maximum length overall is 300 meters. However, the dimension of 150000 DWT vessel is exceeded dimension of the turning basin. 


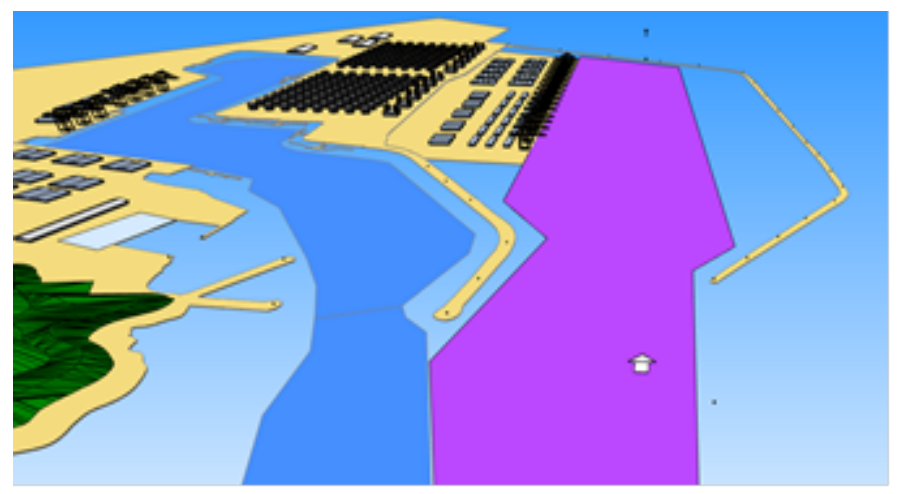

Figure 3: Kuantan Port 3-dimensional Area

\subsection{The Design of New Shipping Channel of New Deep Water Terminal Kuantan Port}

The dimension of large ships that previously called Kuantan Port was used to design the new channel. The data of the ships are shown in Table 1.

Table 1: List Name for LOA, Beam, and Draught for Ships at Kuantan Port

\begin{tabular}{|c|c|c|c|}
\hline Vessels Name & Loa & Beam & Draught \\
\hline Tay Sun 2 & $186.40 \mathrm{~m}$ & $19.6 \mathrm{~m}$ & $9.6 \mathrm{~m}$ \\
\hline Zhonghai & $188.33 \mathrm{~m}$ & $20.2 \mathrm{~m}$ & $8.9 \mathrm{~m}$ \\
\hline Kota Jati & $193.03 \mathrm{~m}$ & $28 \mathrm{~m}$ & $6.1 \mathrm{~m}$ \\
\hline Stolt Sagaland & $182.87 \mathrm{~m}$ & $32.23 \mathrm{~m}$ & $7.5 \mathrm{~m}$ \\
\hline Dubai Energy & $189.87 \mathrm{~m}$ & $32.26 \mathrm{~m}$ & $7.5 \mathrm{~m}$ \\
\hline
\end{tabular}

The design of one-way channel with straits section starts with to determine the overall width of the channel. The equation used to calculate the overall width $\mathrm{W}$ is developed by PIANC in the Harbour Approach Channel Design Guideline [4]

$$
W=W_{B M}+\sum W_{i}+W_{B R}+W_{B G}
$$

Where:

$W_{B M}=$ width of basic manoeuvring lane as a multiple of the design ship's beam B, given in table of the guideline

$W_{i}=$ additional widths to allow for the effects of wind, current etc, given in table of the guideline

$W_{B G}, W_{B R}=$ bank clearance on the 'red' and 'green' sides of the channel, given in table of the guideline

The result of calculation of overall channel width based on Dubai Energy dimension as below:

$W_{B M}=48.39 ; \sum W_{i}=96.78 ; W_{B R}, W_{B G}=3.23$

Therefore, overall channel width $W=148.4$ meter

Based on the result, the minimum overall width of single channel based on the largest ship that called the port is 148.4 meters. This value is far smaller than the proposed width of the new channel, namely 450 meters. However, the single channel is designed for the port. The single channel is more preferred that the double channel is because it has a relatively less risk of collision. Furthermore, the port is not congested, therefore the probability of vessels to move in and out of the port at the same is low. Thus, 
the requirement for two channels at the time is not necessary. Therefore, the proposed width of the new shipping channel of NDWT is safe for operation.

\subsection{Figures New Configuration of Marine Aids to Navigation}

The guidelines used for configuration of marine aids to navigation is IALA Guideline 1078 and IALA NavGuide issued by International Marine Aids to Navigation and Lighthouse Authorities [5]-[7].

Among the IALA Guideline 1078 principles applied in the configuration are as below:

a) Lateral marking of fairway

b) AtoNs positioned at bends and junctions of the fairway

c) AtoNs spaced evenly along the fairway

d) AtoNs on one or both sides of the fairway, were positioned an equal distance from the central axis of the fairway

The result of the configuration of AtoNs for certain area in Kuantan Port is shown in Fig. 4 and Fig. 5.

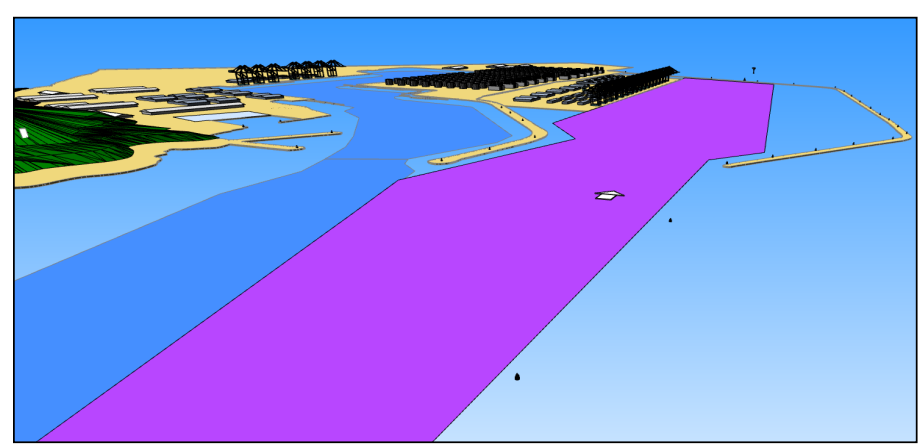

Figure 4: Navigation buoys and leading lights (rectangular)

Fig. 5 shows the lateral marking, namely the navigation buoys are positioned at the edge of the shipping channel with equal distance from one to another. The buoys are marked with a circle dash line, while the leading light marked with a rectangular dash line in Fig. 5. The selected distance between the navigation buoy is 1 nautical mile. This distance would not exceed the distance of the buoys detected during the day time and distance of buoy's navigation light detected the during night time. This would enable the buoys to be continuously tracked during day and night time. For redundancy, if the buoys off-position or loss for whatever reason, the leading lights would provide a safe bearing when perfectly in-line (Fig. 5) to ships that enter or leave the port.

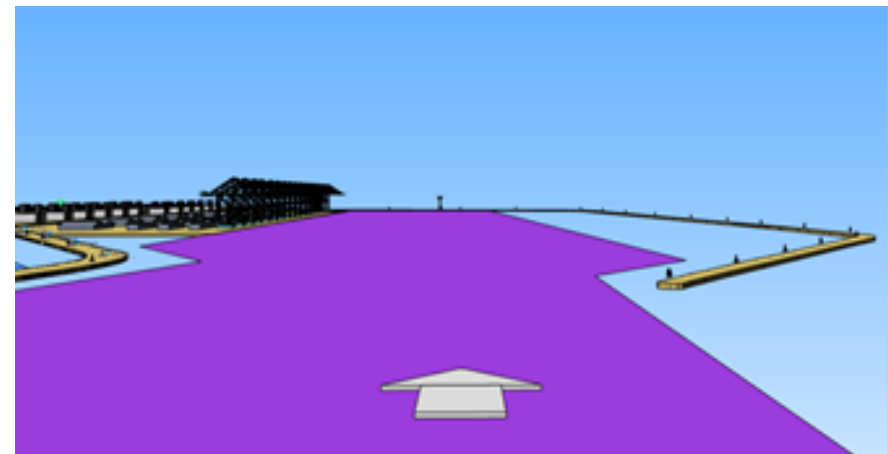

Figure 5: Simulated leading light in perfect in-line that provides a bearing for vessel to enter and leave the NDWT 
The completed three-dimensional area with preliminary configuration of the AtoNs is input into the ship simulator for further assessment by the mariner. This step would verify the configuration of the AtoNs and use to improve the existing configuration.

\section{Conclusion and Recommendation}

Three dimensional area simulation is the most practical and cost effective approach to design a new shipping channel and configure the marine AtoNs. The simulation may reveal problems during the designed stage before the real physical structures and its position is realised. The simulation also provides a good approach for planning and may reduce error upon project completion.

\section{References}

[1] KPC, “Kuantan Port Brochure,” Kuantan, 2018.

[2] The Star, "Kuantan Port upgrade to be ready by mid-2018," The Star, Karak, 07-May-2017.

[3] Lloyd's Register, "Modern ship size definitions," London, 2007.

[4] PIANC, "Harbour Approach Channels Design Guidelines, ” Bruxelles, 2014.

[5] IALA, “Aid to Navigation Manual 2014," St Germain En Laye, 2014.

[6] IALA, "The Use of Aids to Navigation in the Design of Fairways," Saint Germain en Laye, 2011.

[7] IALA, "Maritime Buoyage System and Other Aids to Navigation Contents," Saint Germain en Laye, 2010. 